\title{
Obtención de una sonda específica para evaluar la transcripción del gen STAT5b
}

\author{
Luis Eduardo Díaz, Blanca L. Ortiz, Myriam Sánchez de Gómez \\ Laboratorio de Hormonas, Departamento de Química, \\ Universidad Nacional de Colombia, Bogotá, D.C., Colombia.
}

\begin{abstract}
Se describe la estrategia empleada para clonar, en un vector de expresión, un fragmento de $306 \mathrm{pb}$ del gen de STAT5b de rata, amplificado por la técnica de RT-PCR. Se amplificó una región en el terminal $3^{\prime}$ donde se encuentra la mayor diferencia entre las secuencias del cADN de las isoformas STAT5a y STAT5b de rata. La clonación se logró utilizando el nuevo sistema TOPO-TA recomendado para productos de difícil clonación. El fragmento se subclonó en el vector pBlueScript II SK y se caracterizó mediante secuenciación y análisis de restricción. La subclonación se realizó con el propósito de poder obtener sondas sentido y antisentido de ARN por transcripción in vitro. Esta sonda específica se empleó para cuantificar niveles de mARN de STAT5b en hígado de ratas macho mediante la técnica de hibridización en solución o ensayo de protección de ARNasas.
\end{abstract}

Palabras clave: RT-PCF, GH, STAT5b, hibridización en solución.

\section{Obtaining a specific probe to evaluate STAT5b gene transcription}

The strategy for cloning a 306 bp rat STAT5b fragment, amplified by RT-PCR, into an expression vector is described. The main difference between STAT5a and STAT5b lies within the 3' region of their respective cDNAs, therefore a fragment in this region was amplified. Cloning was achieved by using the new system TOPO-TA recommended, for products difficult to be cloned. The fragment was subcloned into pBlueScript II SK vector and characterized by sequencing and restriction analysis. Subcloning was done in order to obtain sense and antisense RNA probes by in vitro transcription. This specific probe has been used to quantify STAT5b mRNA levels in liver from male rats, by a solution hybridization RNAase protection assay.

Key words: RT-PCR, GH, STAT5b, solution hybridization assay.

La hormona de crecimiento $(\mathrm{GH})$ ejerce múltiples funciones, entre las cuales se encuentran: el incremento del crecimiento lineal en mamíferos (1), el incremento del número de células en los tejidos blanco y la acción en el metabolismo de carbohidratos, lípidos y proteínas (2). Pese a esta gran variedad de funciones atribuidas a la $\mathrm{GH}$, hasta el momento sólo se han descrito unas pocas vías de transducción de su señal, entre las cuales se incluye la vía directa al núcleo que consiste en la unión de la GH a su receptor (GHR) en células blanco, lo cual provoca la dimerización del receptor

\footnotetext{
Correspondencia: Myriam Sánchez de Gómez mygomez@ciencias.unal.edu.co
}

Recibido: 21/02/01; aceptado: 07/05/01 y la asociación con JAK2, una proteína de la familia Janus, de tirosinas cinasas. Esta asociación induce la fosforilación de la cinasa, del receptor mismo y de otras proteínas citoplasmáticas denominadas STAT (transductores de señales y activadores de transcripción) (3). Estas últimas se dimerizan y se translocan al núcleo, donde se unen a secuencias específicas en el ADN para promover la transcripción de genes específicos (4).

Hasta el momento, se han clonado 8 miembros de la familia STAT: STAT $1 \alpha$, STAT $1 \beta$, STAT2, STAT3, STAT4, STAT5a, STAT5b, STAT6 y el producto del gen Marelle de Drosophila (5). Las proteínas STAT han sido estudiadas en detalle y se dispone ahora de modelos knockoutpara todas, excepto para STAT2. En ratones se ha encontrado 
que la carencia (knockout) de STAT3 conlleva a una letalidad fetal, y la de STAT1, STAT4 y STAT6 resultan en inmunodeficiencias consistentes con la alteración en la señalización de las citocinas específicas que activan cada una de estas proteínas. De STAT5, se han identificado dos isoformas denominadas STAT5a y STAT5b (3) las cuales poseen un $96 \%$ de identidad en la secuencia de aminoácidos y contienen 793 y 786 aminoácidos, respectivamente, son codificadas por genes separados y poseen diferentes funciones fisiológicas (6). Estudios recientes con ratones que carecen de STAT5a, muestran un fenotipo específico consistente en un desarrollo incompleto de la glándula mamaria durante el embarazo y problemas de lactancia, sin evidencias de defectos en el crecimiento (7). Por el contrario, la carencia de STAT5b en ratones, produce la pérdida del dimorfismo sexual en la expresión hepática de genes y retardo en el crecimiento corporal (8).

En un trabajo previo en nuestro laboratorio, empleando una sonda para cuantificar el mARN de las isoformas STAT5 en rata, se demostró la presencia de una mayor cantidad de mARN de STAT5 en hígado que en linfocitos de timo de ratas (9). Actualmente, el interés se centra en establecer el nivel de transcripción diferencial de estos genes en tejidos de rata. En este trabajo se describe la amplificación de un fragmento en el extremo $3^{1}$ del cADN de STAT5b, región en la cual divergen las secuencias de STAT5a y STAT5b; se describe, así mismo, la obtención de la sonda específica, la comprobación de su identidad y su utilización en la cuantificación del mARN de STAT5b en hígado de rata, por el método de protección de ARNasas.

\section{Materiales y métodos}

\section{Animales}

Se emplearon ratas Wistar macho, de 6 a 8 semanas de edad suministradas por el Bioterio del Departamento de Farmacia de la Universidad Nacional de Colombia. En cada ocasión, luego de sacrificar el animal por decapitación, se disectó el hígado, el cual se empleó inmediatamente para la extracción de ARN total.

\section{Extracción y cuantificación del ARN total}

La extracción de ARN total y de ADN de hígado se realizó empleando el reactivo trizol (Gibco BRL, Life Technologies), el cual es una modificación del método de Chomczynski y Sacchi (10), que permite aislar ARN total, ADN y proteínas de células y tejidos. Las muestras extraidas se almacenaron a $-70{ }^{\circ} \mathrm{C}$ hasta el momento de análisis. Las concentraciones y la calidad de ARN total se determinaron espectrofotométricamente y se visualizaron mediante electroforesis en gel de agarosa y bufferTBE 0,5X (Tris 0,089 M, ácido bórico $0,089 \mathrm{M}$, EDTA $0.002 \mathrm{M}$ ). Los productos se observaron con transiluminador de luz ultravioleta y la imagen se captó con una cámara polaroid MP4.

\section{Amplificación por PCR}

Síntesis de los oligonucleótidos iniciadores. Para el diseño y la síntesis de los oligonucleótidos iniciadores, se empleó la secuencia publicada del CADN de STAT5b de rata (11). La secuencia del oligonucleótido sentido (primer 5') es: 5'-GAG AA'A GCT TCG TGT GAG CCC GCC ACC-3' (sitio de corte con la enzima Hind III, subrayado).

La secuencia del oligonucleótido antisentido (primer $3^{\prime}$ ) es: 5'-CGC G'AA TTC GTC ATG ACT GCG CGT-3' (sitio de corte con la enzima EcoR I, subrayado).

La síntesis de los oligonucleótidos se encargó a Gibco (Gibco BRL Life Technologies, Gaithersburg, MD USA).

\section{Técnica de RT-PCR}

Para lograr la amplificación del fragmento deseado se utilizó la técnica combinada Acces RT-PCR (Promega, Madison, WI USA). Partiendo de ARN total extraido de hígado de rata, se sintetizó la primera cadena de ADN y, luego, se realizó la amplificación con Vent ADN polimerasa. Se empleó un termociclador marca Perkin Elmer (Gene Amp PCR System 2.400), con el siguiente programa: un ciclo: desnaturalización inicial a $94{ }^{\circ} \mathrm{C} / 5 \mathrm{~min}$; cuarenta ciclos: desnaturalización inicial a $94^{\circ} \mathrm{C} / 30 \mathrm{seg}$; alineación a $70^{\circ} \mathrm{C} / 45 \mathrm{seg}$ y extensión a $72{ }^{\circ} \mathrm{C} / 30 \mathrm{seg}$; un ciclo: extensión a $72{ }^{\circ} \mathrm{C} / 5 \mathrm{~min}$. Finalizado el proceso, se realizó la electroforesis en gel de agarosa al $1 \%$ y buffer 
TAE $1 X$ (Tris-acetato 0,04 M, EDTA 0,02 M, pH $8,5)$; los productos se visualizaron con transiluminador de luz ultravioleta y la imagen se captó con una cámara polaroid. El resto del volumen de reacción se purificó utilizando el estuche de Glass Max (Gibco BRL Life Technologies, Gaithersburg, MD USA).

\section{Clonación del producto de PCR}

Se empleó inicialmente el vector pBlueScript SK +/- (Stratagene, La Jolla, CA) que contiene el gen de resistencia a la ampicilina, dos sitios promotores, uno para la ARN polimerasa T7 $y$ otro para la T3, el gen Lac Z y sitios de alineación para los iniciadores M13 directo y reverso; este vector se digirió con la enzima EcoR I a $37^{\circ} \mathrm{C}$; luego, se inactivó la enzima por calentamiento a $65^{\circ} \mathrm{C}$ y se llevó a cabo la digestión con la enzima Hind III ajustando las condiciones óptimas. El producto de PCR se digirió con estas mismas enzimas $y$, luego, diferentes relaciones molares inserto:vector se trataron con T4 ADN ligasa y se incubaron a $16{ }^{\circ} \mathrm{C}$ durante toda la noche. La ligación en estas condiciones no funcionó y se requirió emplear el vector pCR 2.1-TOPO (Invitrogen, Carlsbad CA) el cual se puede trasformar en cualquier cepa corriente, contiene el gen lac $Z$, un gen de resistencia a kanamicina, un gen de resistencia a ampicilina, un sitio promotor para ARN polimerasa T7, sitios de alineación para los iniciadores M13 directo y reverso. Este vector está especialmente indicado para la clonación de amplificados con Taq ADN polimerasa difíciles de clonar en otros sistemas. El producto amplificado con Vent ADN polimerasa se incubó por $10 \mathrm{~min}$ en presencia de Taq ADN polimerasa y desoxinucleótidos trifosfato (dNTPs). Luego, se procedió a la ligación empleando una relación inserto-vector de 100:1 e incubación con T4 ADN ligasa a $16{ }^{\circ} \mathrm{C}$ durante la noche.

\section{Transformación y selección de las transformantes}

Con $2 \mu \mathrm{l}$ del producto ligado, se transformaron las células competentes JM-109 mediante electroporación en un equipo E. coli pulser (Biorad, Hercules, CA), y se seleccionaron los transformantes adicionando en el medio sólido de cultivo (LB sólido conteniendo $100 \mu \mathrm{g} / \mathrm{ml}$ de ampicilina), IPTG (8 $\mathrm{ml}$ de una solución 0,5 M), y
X-gal (100 $\mathrm{ml}$ de una solución al 2\% en dimetilformamida). Las colonias recombinantes con un gen lac $Z$ interrumpido no sintetizaron Bgalactosidasa y dieron colonias blancas.

Algunas de las colonias blancas presentes fueron reinoculadas individualmente en medio LB líquido con ampicilina $(100 \mu \mathrm{g} / \mathrm{ml})$ para realizar la extracción del ADN plasmídico empleando el estuche Plasmid mini kit (Qiagen, Chatsworth, CA)

Este ADN plasmídico se secuenció empleando el sistema $\mathrm{ABI} 373 \mathrm{~A}$ DNA sequencing systems.

\section{Subclonación del fragmento en pBlueScript II SK (+/-)}

Con el propósito de emplear el producto clonado para realizar transcripción in vitro se procedió a subclonarlo en el vector pBlueScript II SK (+/-). Para este fin, se realizó una extracción de ADN plasmídico empleando el estuche plasmid midi kit (Quiagen, Chatsworth, CA).

EI plásmido STAT5b-pCR-TOPO y el vector pBlueScript II se digirieron, por separado, con la enzima EcoR I; luego, se ligaron en una relación 100:1 con T4 ADN ligasa a $16^{\circ} \mathrm{C}$ durante la noche. La transformación de células competentes y la selección inicial de colonias transformantes se realizó de la manera ya descrita. Posteriormente, se efectuó una segunda selección tomando algunas de las colonias blancas y reinoculándolas simultáneamente tanto en cajas de LBkanamicina, $50 \mu \mathrm{g} / \mathrm{ml}$ como en las cajas LBampicilina, $100 \mu \mathrm{g} / \mathrm{ml}$. Las colonias que crecieron en las cajas con LB-ampicilina pero no en LBkanamicina, fueron utilizadas para aislar el ADN plasmídico empleando el estuche plasmid mini kit (Quiagen, Chatsworth CA) .

\section{Identificación del producto clonado}

Análisis de restricción. Para determinar si los plásmidos extraidos contenían el inserto deseado, éstos fueron tratados con la enzima EcoR I que genera en los recombinantes un fragmento de 326 pb y otro del tamaño del vector. Se hizo tratamiento con las enzimas Sac II y Kpn I por separado, que tienen un único sitio de corte en el vector y ninguno en el inserto, de tal manera que la inserción (en el vector pBlueScript II SK +/-) generará en ambos 
casos una única banda de 3281 pb. Además, se digirieron los plásmidos por separado con las enzimas Bam HI y Pst I las cuales cortan tanto al inserto (en un solo sitio) como al vector (en un solo sitio) para determinar el sentido de inserción del fragmento en el vector.

\section{Cuantificación del mARN de STAT5b en hígado de rata}

Transcripción in vitro. Con el propósito de sintetizar ribosondas sentido y antisentido, se procedió a transcribir in vitro la sonda o producto clonado, siguiendo un protocolo adaptado de Promega (Promega Corporation, 1991). Para la síntesis de la ribosonda antisentido, la sonda de STAT5b se linearizó con la enzima Kpn I. Aproximadamente, $800 \mathrm{ng}$ de este CADN plantilla se transcribieron con T3 ARN polimerasa $(50 \mathrm{U} / \mathrm{\mu l})$ en presencia de $35_{\mathrm{s}}$-UTP (actividad específica, $1.000 \mathrm{Ci} / \mathrm{mmol}$, Amersham, Buckinghanshire, England) incubando por $90 \mathrm{~min}$ a $37^{\circ} \mathrm{C}$. Luego de una extracción con fenol/cloroformo, los nucleótidos no incorporados se removieron por fraccionamiento a través de una columna Nick empacada con Sephadex G-50 (Pharmacia, Estocolmo, Suecia) y la actividad específica se determinó por precipitación con ácido tricloroacético (TCA), captura sobre filtros de fibra de vidrio (GF/C Whatman) y cuantificación en contador de centelleo líquido (Beckman, modelo LS 5000 TD).

Para la síntesis de la cadena de ARN sentido, se siguió el procedimiento antes descrito excepto que la sonda de STAT5b se linearizó con la enzima Sac II y se transcribió in vitro con T7 ARN polimerasa (20 U/ $\mu \mathrm{g}$ de plásmido) incubando por 90 min a $37^{\circ} \mathrm{C}$. La concentración final de transcrito ARN sentido se determinó espectrofotométricamente. Los transcritos sentido y antisentido de ARN se dividieron en alícuotas y se almacenaron a $-70^{\circ} \mathrm{C}$ hasta su uso.

\section{Ensayo de protección de ribonucleasa $A$ o hibridización en solución}

Se siguió el método desarrollado por Durnam y Palmiter (12), modificado por Moller (13).

La sonda de ARN antisentido radiomarcada $\left(5,2 \times 10^{8} \mathrm{cpm} / \mu \mathrm{g}\right)$ se hibridizó en solución con concentraciones crecientes de sonda de ARN sentido $(0-10 \mathrm{pg})$, para construir la curva patrón o con cantidades variables de las muestras de ARN total de hígado de rata $(10,20$ y $40 \mu \mathrm{g})$. Las hibridizaciones se hicieron por $18 \mathrm{~h}$ a $70{ }^{\circ} \mathrm{C}$ en presencia de $25 \%$ de formamida, 0,75 $\mathrm{mM} \mathrm{DTT}$, $0,6 \mathrm{M} \mathrm{NaCl}, 20 \mathrm{mM}$ Tris y $4 \mathrm{mM}$ EDTA, en un volumen de reacción de $40 \mu \mathrm{l}$ cubierto con aceite de parafina. EI ARN no hibridizado se degradó, luego, por adición de $1 \mathrm{ml}$ de ARNasa A $(40 \mu \mathrm{g} /$ $\mathrm{ml})$, ADN de esperma de salmón $(100 \mu \mathrm{g} / \mathrm{ml}) \mathrm{e}$ incubación a $37^{\circ} \mathrm{C}$ por $45 \mathrm{~min}$. Los híbridos resistentes a la acción de la ribonucleasa se precipitaron por adición de $100 \mu$ de TCA 6 M e incubación en hielo por $30 \mathrm{~min}$. Los híbridos se capturaron por filtración a través de filtros GF/C, Whatman; se lavaron una vez con TCA al $43 \%$ en pirofosfato de sodio al $1 \%$ y dos veces con etanol al $70 \%$. La radioactividad hibridizada se midió en un contador de centelleo líquido.

La curva patrón se construyó graficando la radiactividad hibridizada por la ribosonda sentido, $\mathrm{cpm}$ hibridizadas, contra las concentraciones crecientes de dicha ribosonda de ARN sentido expresadas en picogramos (pg). Finalmente, los resultados se expresaron como fg mARN-STAT5b/ $\mu \mathrm{g}$ de ARN. Como control negativo, se usó una sonda de $316 \mathrm{pb}$ del gen gliceraldehído 3-fosfato deshidrogenasa (GAPDH) de rata, derivada de los exones 5-8 (nucleótidos 369-685) (Ambion). El fragmento de gen GAPDH está insertado entre los sitios Sac I y Bam HI del vector de transcripción TRIPLEscript, el cual contiene promotores SP6, T7 y T3 permitiendo el uso de cualquiera de estas enzimas para sintetizar los transcritos. La sonda de GAPDH se digirió con Bam HI y se usó T7 ARN polimerasa para la transcripción de la sonda antisentido en presencia de $35_{\mathrm{s}}$-UTP.

\section{Resultados}

\section{Amplificación por RT-PCR}

Mediante la técnica Acces RT-PCR (Promega, Madison, WI, USA) se logró amplificar el fragmento esperado de $326 \mathrm{pb}$, tal como se muestra en la figura 1 (carriles 3-7) que corresponde a la electroforesis de los productos obtenidos. En la amplificación se empleó una unidad de Vent ADN polimerasa en $50 \mu \mathrm{l}$ de 


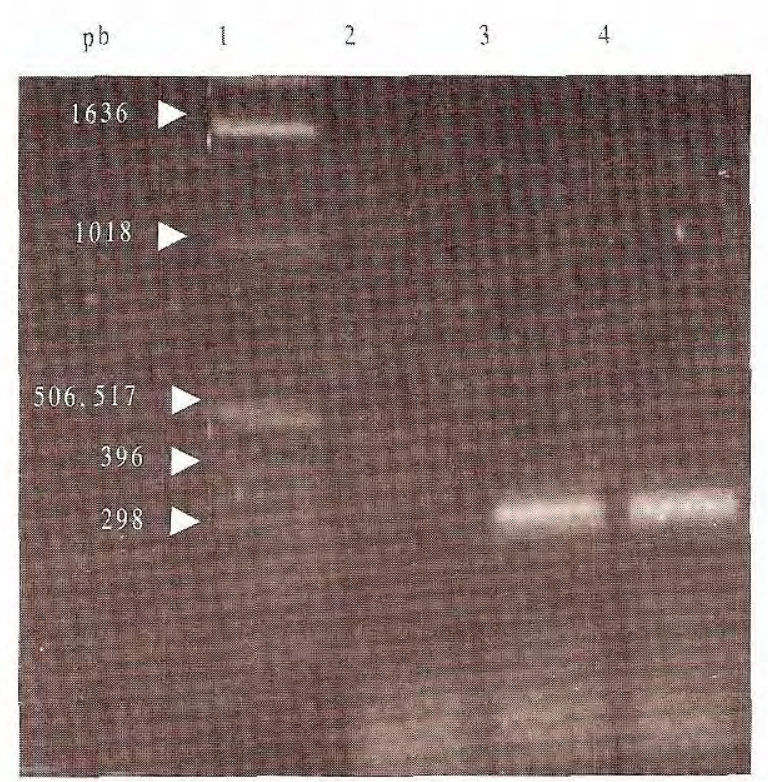

Figura 1. Electroforesis de los productos de RT-PCR obtenidos con el sistema Acces RT-PCR y Vent ADN polimerasa. Carril $1.5 \mu \mathrm{l}$ marcador de peso molecular $1 \mathrm{~kb}$ DNA Ladder (Gibco BRL Life Technologies). Carril 2. Control negativo. Carriles 3-4. $5 \mu \mathrm{l}$ producto de RT-PCR. Electroforesis en gel de agarosa al $1 \%$, bromuro de etidio $0,5 \mu \mathrm{g} / \mathrm{ml}$ y buffer TAE, durante 20 minutos a 75 voltios.

volumen de reacción, una concentración final de MgSO4 de $2 \mathrm{mM}$ y una temperatura de alineación de $70^{\circ} \mathrm{C}$. No se observaron amplificaciones no específicas, excepto las bandas de menor tamaño correspondientes posiblemente a dímeros de los oligonucleótidos iniciadores.

\section{Clonación y subclonación del producto amplificado}

El producto amplificado resultó difícil de clonar ya que los ensayos que se hicieron con el vector pBlueScript II SK +/-, resultaron fallidos. Se recurrió al vector $\mathrm{PCR} \otimes T O P O$, recomendado para productos de difícil clonación. Se obtuvieron colonias recombinantes de las cuales se aisló el ADN plasmídico y la inserción se comprobó por secuenciación (resultados no mostrados). Para la subclonación se empleó el vector pBlueScript II SK +/- digerido con la enzima EcoR I. Igualmente el plásmido STAT5b-pCR 2.1TOPO se digirió con la enzima EcoR I liberándose un fragmento de $320 \mathrm{pb}$ (inserto), junto con la banda correspondiente al vector pCR®2.1TOPO, como se muestra en la figura 2, correspondiente a la electroforesis de $10 \mu \mathrm{l}$ del producto de la digestión.

Las células fueron transformadas como se mencionó anteriormente, empleando $2 \mu \mathrm{l}$ del producto de ligación. El método de selección fue diseñado con base en el color de la colonia y los genes de resistencia a antibióticos de cada uno de los vectores. La mezcla de transformación se sembró en cajas de medio LB sólido con ampicilina, tras la incubación debida fueron picadas las colonias blancas y sembradas simultáneamente en cajas con ampicilina y kanamicina. Debido a que el pBlueScript II SK +/no posee el gen de resistencia a kanamicina fueron las colonias que crecieron en ampicilina y no en kanamicina las escogidas para llevar a cabo el aislamiento del ADN plasmídico. Se obtuvieron cuatro colonias con tales características.

\section{Identificación del producto clonado}

Análisis de restricción. Para determinar si los plásmidos extraidos contenían el inserto deseado, fueron tratados con la enzima EcoR I. La electroforesis de los productos obtenidos (figura 3) mostró para uno solo de los plásmidos la banda de $326 \mathrm{pb}$ correspondiente al inserto liberado (carril 3).

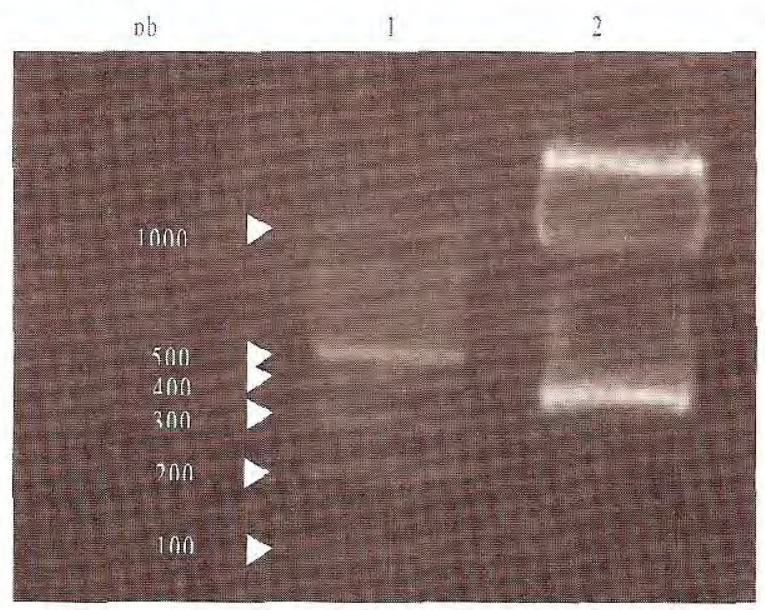

Figura 2. Electroforesis de los productos de digestión con EcoR I del plásmido pCRß2.1TOPO-STAT5b. Carril 1. $5 \mu \mathrm{l}$ marcador de peso molecular 100 pb DNA Ladder (Promega). Carril 2. $10 \mu \mathrm{l}$ de plásmido pCR 2.1TOPO-STAT5b cortado con EcoR I. Electroforesis en gel de agarosa al $4 \%$, bromuro de etidio $0.5 \mu \mathrm{g} / \mathrm{ml}$ y buffer TAE, durante 20 minutos a 75 voltios. 
Luego, el plásmido pBlueScript II SK-STAT5b se trató, por separado, con las enzimas Kpn I y Sac II obteniéndose en cada caso, fragmentos de tamaño mayor al vector no recombinante, comprobándose, así, la inserción (resultados no mostrados).

Para determinar el sentido en que se ligó el fragmento en el vector, se digirió el plásmido, por separado, con las enzimas Pst I y Bam HI. En la figura 4 se muestra la electroforesis de los productos obtenidos. Se observa que del corte con Pst I resultó una banda de 250 pb y otra de $3.000 \mathrm{pb}$ (carril 2) aproximadamente, mientras que al cortar con Bam HI sólo se observó la banda de mayor tamaño pues la otra, de menos de $200 \mathrm{pb}$ no se alcanzó a visualizar (carril 3). De esta manera, se determinó que el fragmento se insertó en sentido contrario al marco de lectura del vector.

\section{Cuantificación del mARN de STAT5b en hígado de rata}

En la transcripción in vitro, se obtuvo una ribosonda antisentido con actividad específica de $5,2 \times 10^{8}$ $\mathrm{cpm} / \mu \mathrm{g}$. Hibridizando en solución esta ribosonda antisentido marcada con cantidades conocidas ( 0 a $10 \mathrm{pg}$ ) de patrón de ribosonda sentido, se obtuvo

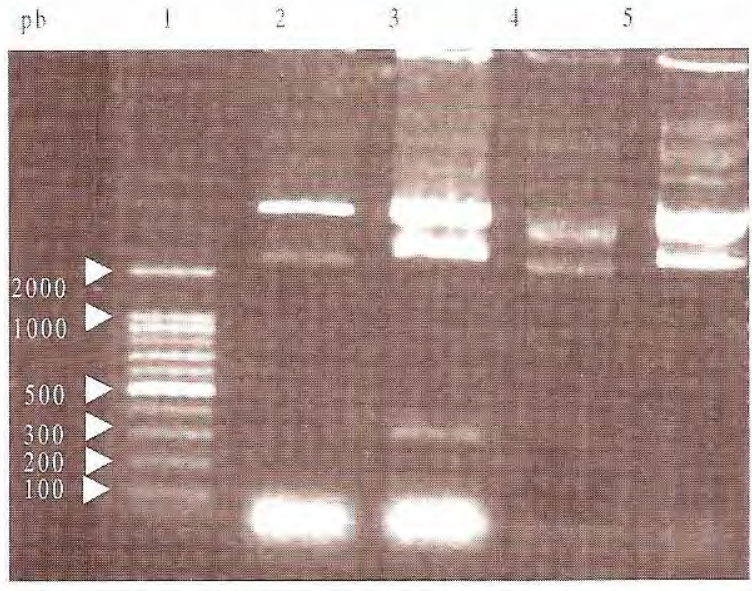

Figura 3. Electroforesis de los productos de la digestión con EcoR I de los posibles plásmidos pBlueScript-STAT5b. Carril $1.5 \mu \mathrm{l}$ Marcador de Peso Molecular $100 \mathrm{pb}$ DNA Ladder (Promega). Carriles 2-5. $10 \mu$ l posibles plásmicios pBlueScriptSTAT5b cortados con EcoR I. Electroforesis en gel de agarosa al $4 \%$, bromuro de etidio $0,5 \mu \mathrm{g} / \mathrm{ml}$ y buffer TAE; durante 20 minutos a 75 voltios. la curva típica dosis-respuesta o curva patrón que se muestra en la figura 5.

En el cuadro 1 se muestran los resultados de la cuantificación de mARN de STAT5b en las muestras de ARN total de hígado de ratas macho en condiciones normales.

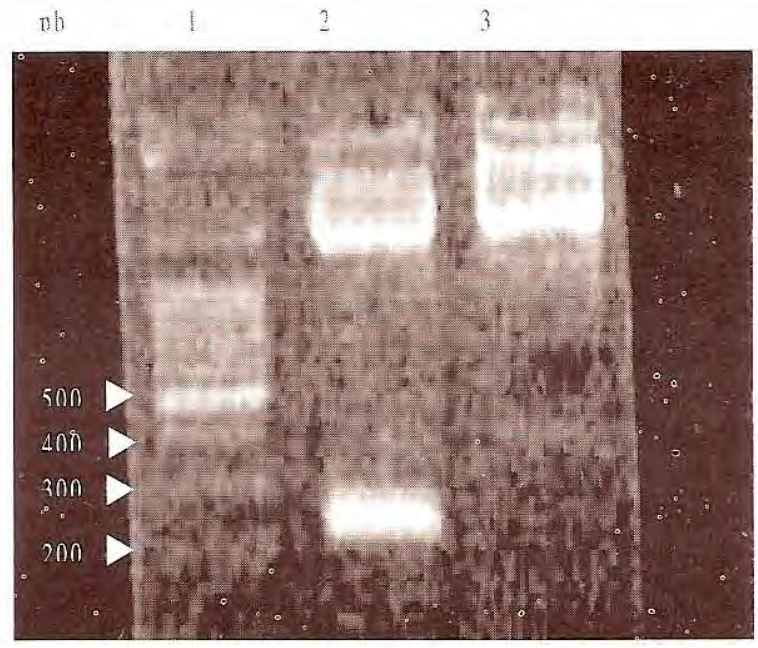

Figura 4. Electroforesis de los productos de la digestión del plásmido pBlueScript-STAT5b con Pst I y BamH I. Carril $1.5 \mu \mathrm{l}$ Marcador de Peso Molecular 100 pb DNA Ladder (Promega). Carril 2. $10 \mu \mathrm{l}$ de plásmido pBlueScript-STAT5b cortado con Pst I. Carril 3. $10 \mu \mathrm{l}$ de plásmido pBlueScript-STAT5b cortado con Bam HI. Electroforesis en gel de agarosa al $4 \%$, bromuro de etidio $0,5 \mu \mathrm{g} / \mathrm{ml}$ y buffer TAE; durante 20 minutos a 75 voltios.

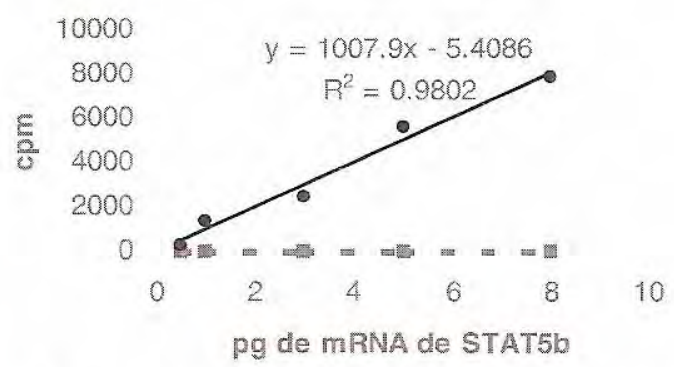

Figura 5. Curva patrón del ensayo de protección de ribonucleasa $A$. La sonda STAT5b antisentido radiomarcada. se hibridizó con cantidades crecientes de patrón de sonda STAT5b sentido. Se muestra como control negativo (línea punteada) el resultado de hibridizar la sonda antisentido de GAPDH con cantidades crecientes de sonda sentido de STAT5b. Cada determinación corresponde al promedio de dos replicados. 
Cuadro 1. Cuantificación de mRNA de STAT5b en hígado de ratas macho $(n=4)$. Cada muestra se analizó en tres niveles de concentración y se indica el promedio + D.E.

\begin{tabular}{cc}
\hline Muestra & fg de mARN de STAT5b/ $\mathbf{\mu g}$ ARN total \\
\hline 1 & $75,0+0,48$ \\
2 & $86,8+0,62$ \\
3 & $77,5+1,35$ \\
4 & $83,6+1,12$ \\
\hline
\end{tabular}

\section{Discusión}

Los estudios realizados hasta el momento, han evaluado principalmente la presencia y estado de activación de las isoformas STAT5a y STAT5b en diversos tejidos. De esta forma, se ha encontrado que la STAT5a es la principal forma de STAT5 que se activa por acción de la prolactina en la glándula mamaria, donde se requiere para su desarrollo y para la lactogénesis (7). Por el contrario, la STAT5b es la principal forma de STAT5 en el hígado (11), donde se activa en respuesta al estímulo por el patrón intermitente de secreción de $\mathrm{GH}$, característico de las ratas macho adultas, pero no por el patrón de secreción casi continuo característico de las ratas hembra adultas (14). Los modelos de mutación específica de cada uno de los genes de STAT5, han permitido establecer que la STAT5b se requiere para mantener el dimorfismo sexual en las respuesta a la GH (8) y concluir que las isoformas STAT5a y STAT5b se requieren, individual o conjuntamente, en casi todas las respuestas biológicas asociadas con la $\mathrm{GH}(15,16)$.

Los trabajos realizados para medir la expresión de los genes de STAT5, por Northern blot, han mostrado que ambos se expresan en forma similar en casi todos los tejidos de ratón, con excepción del cerebro y el músculo, donde STAT5a es predominante (3). En ratas, el gen de STAT5b se expresa mucho más en el hígado (11). Por ensayos de hibridización en solución, empleando una sonda que reconoce tanto la forma a como la $b$, se ha encontrado una mayor expresión de STAT5 en hígado que en linfocitos de timo de ratas hembra (9).

En este trabajo, el diseño de los oligonucleótidos iniciadores para amplificar el fragmento de STAT5b por PCR, se dificultó por la alta homología de las isoformas STAT5a y $b$, las cuales divergen únicamente en 8 aminoácidos en el terminal carboxilo. El considerar sólo esta secuencia daría un amplificado muy corto ( $90 \mathrm{pb})$, inadecuado para el uso futuro de esta sonda en la hibridización en solución, para la cual se requieren sondas de ARN de mínimo $200 \mathrm{pb}$ (17). Por tanto, hubo necesidad de ampliar la zona a considerar y finalmente, se decidió amplificar la región entre los nucleótidos 2.179 a 2.475 , con la cual se esperaba obtener un amplificado de $326 \mathrm{pb}$. El diseño de los oligonucleótidos fue el adecuado puesto que desde un principio se obtuvo la amplificación por PCR del producto esperado de $326 \mathrm{pb}$.

La síntesis se realizó empleando una combinación del sistema Acces RT-PCR y Vent ADN polimerasa, con lo cual se logró reducir la reacción de amplificación de los dímeros de los oligonucleótidos iniciadores y los problemas de inestabilidad del CADN de primera cadena. El producto de PCR no pudo clonarse en los vectores corrientes, pGem 4Z, pBlueScript II SK y pMos Blue, y sólo se logró con el vector pCR2.1TOPOTA, específico para clonar fragmentos de PCR obtenidos con Taq ADN polimerasa y difíciles de clonar en otras condiciones. La secuencia del plásmido recombinante así obtenido mostró contener la secuencia correcta del fragmento de STAT5b. El resultado mostró, además, que realmente el fragmento de STAT5b era muy difícil de clonar ya que a pesar de la alta eficiencia de transformación del vector pCR2.1-TOPOTA, se obtuvieron muy pocas colonias blancas $(5,4 \%)$ y al realizar la secuencia completa de los ADN plasmídicos aislados, sólo dos contenían el inserto ( $1,8 \%$ del total de colonias). Se podría pensar que el número tan bajo de colonias recombinantes podría deberse a que el plásmido fuera tóxico para las células.

Se pudo asegurar la especificidad de la sonda obtenida puesto que su secuencia coincide exacta y únicamente con la de STAT5b (código Genbank RNSTAT5BG) y, además, al emplear cADN de STAT5a, como plantilla en la PCR, no se obtuvo ningún amplificado (resultado no mostrado).

Cuando este trabajo se encontraba avanzado, se publicó un estudio en ratón, en el cual se utilizó 
también el método de RT-PCR, pero seguido de una etapa de digestión con la enzima Nco I sitio presente en el amplificado de STAT5a. La digestión selectiva de los productos de PCR permite distinguir el fragmento de PCR amplificado del cADN de STAT5a, del fragmento amplificado del cADN de STAT5b (18). Mediante este análisis de restricción y la electroforesis de los fragmentos digeridos y no digeridos, es posible evaluar patrones relativos de expresión por medio de densitometría. En dicho estudio, se encontró un mayor nivel de mARN de STAT5b en hígado de ratones macho y hembra. La estrategia seleccionada en el presente trabajo permitió amplificar una región del cADN con un potencial de discriminación alto para reconocer transcritos de la isoforma STAT5b de rata. El empleo de esta ribosonda en la cuantificación del mARN de STAT5b en hígado de ratas macho, mostró un nivel promedio de $82,72+0,9 \mathrm{fg}$ de mARN de STAT5b/ $\mu \mathrm{g}$ ARN total, para dicha expresión. En la actualidad, con la sonda obtenida, se avanza en el estudio de la expresión diferencial del gen STAT5b en diversos tejidos de rata y en cultivos celulares, en condiciones basales y postestímulo con $\mathrm{GH}$.

\section{Agradecimientos}

Los autores expresan su agradecimiento al Programa IPICS, Universidad de Uppsala, Suecia, a los Laboratorios CorpoGen, Bogotá, Colombia, a los Laboratorios Pharmacia \& Upjohn AB, Estocolmo, Suecia, y al Departamento de Química de la Universidad Nacional de Bogotá, Colombia.

\section{Referencias}

1. Kelly P, Dinaje J, Postel M, Edery M. The prolactin/ growth hormone receptor family. Endocr Rev 1991;12: 235-51.

2. Morgan B, Morgan R. Hormonas. Miéxico: Editorial Diana; 1997. p.75-9.

3. Liu X, Robinson G, Gouilleux F, Groner B, Hennighausen L. Cloning and expression of STAT5 and an additional homologue (STAT5b) involved in prolactin signal transduction in mouse mammary tissue. Proc Natl Acad Sci 1995;92:8831-5.

4. Darnell JE, Kerr MI, Stark GR. JAK-STAT pathways and transcriptional activation in response to IFNs and other extracellular signalling proteins. Science 1994;264: 1415-21.

5. Wood T. Growth hormone, JAKs and STATs: a model cytokine signal transduction system. Sundbyberg, Sweden: Larserics Print AB; 1996. p.32-4.

6. Hee K, Waxman D. Growth hormone, but not prolactin, maintains low-level activation of STAT5a and STAT5b in female rat liver. Endocrinology 1999;11:5126-35.

7. Liu X, Robinson G, Wagner K, Garrett L, WynshawBoris A, Hennighausen L. STAT5a is mandatory for adult mammary gland development and lactogenesis. Genes Dev 1997;12:179-86.

8. Udy G, Raewyhn P, Toweres R, Snell R, Wilkins J, Park S, et al. Requirement of STAT5b for sexual dimorphism of body growth rates and liver gene expression. Proc Natl Acad Sci 1997;94:7239-44.

9. Ortiz B, Sánchez-Gómez M, Norstedt G. Obtención de una sonda para cuantificar el mARN del factor activador de la transcripción STAT5 en rata. Biomédica 1998;18:185-91.

10. Chomczynski T, Sacchi N. Single-step method of RNA extraction by acid guanidium thiocyanate-phenolchloroform extraction. Ann Biochem 1987;162:156-9.

11. Ripperger J, Fritz S, Fey G. Transcription factors STAT3 and STAT5b are present in rat liver nuclei late in an acute phase response and bind interleukin- 6 response elements. J Biol Chem 1995;270:29998-30006.

12. Durnam DM, Paimiter RP. A practical approach for quantitating specific mRNA by solution hybridization. Ann Biochem 1983;131:383-93.

13. Moller C. Aspects of the mechanism of growth hormone action (thesis). Karolinska Institute, Sweden; 1982.

14. Waxman D, Ram P, Park S, Choi H. Intermittent plasma growth hormone triggers tyrosin phosphorylation and nuclear translocation of a liver-expressed STAT5-related DNA binding protein. J Biol Chem 1995;270:1326270

15. Teglund S, McKay C, Schuetz E, Deursen J, Stravopodis D, Wang D, et al. STAT5a and STAT5b proteins have essential and nonessential, or redudant, roles in cytokine responses. Cell 1998;93:841-50.

16. Davey $\mathbf{H}$, Wilkins $\mathbf{R}$, Waxman D. STAT5 signaling in sexually dimorphic gene expression and growth patterns. Am J Hum Genet 1999;65:959-65.

17. Farrel R. RNA methodologies. A laboratory guide for isolation and characterization. New York: Academic Press; 1993. p.221-34.

18. Park S, Liu X, Hennighausen L, Davey H, Waxman D. Distintive roles of stat5a and stat $5 b$ in sexual dimorphism of hepatic p450 gene expression. J Biol Chem 1999;274:7421-30. 